\title{
Comparisons of the Severity between the Kidney and Non-Kidney Disabled Persons by the Number of Chronic Diseases, Out-of-Pocket Expenditure, and Quality of Life: using Korea Health Panel
}

\section{Sun Mi Shin}

Joongbu University https://orcid.org/0000-0002-5519-2412

Hee Woo Lee ( $\nabla$ md.leehw@gmail.com )

https://orcid.org/0000-0002-0327-3632

\section{Research article}

Keywords: End-Stage Renal Disease, Kidney Disabled, Number of chronic diseases, Out-of-pocket expenditure, Quality of life

Posted Date: October 24th, 2019

DOl: https://doi.org/10.21203/rs.2.16413/v1

License: (a) (i) This work is licensed under a Creative Commons Attribution 4.0 International License. Read Full License 


\section{Abstract}

Background: Due to End-Stage Renal Disease, patients who have received dialysis for more than three months or who have already received a kidney transplant are eligible for registration as the Kidney Disabled in Korea. This study aimed to identify the severity between the Kidney and Non-Kidney Disabled by the number of chronic diseases, out-of-pocket expenditure, and quality of life.

Methods: This study used the Korean Health Panel from 2009 to 2013. We compared the number of chronic diseases, out-of-pocket expenditure, and quality of life between the Kidney and Non-Kidney Disabled. The Non-Kidney Disabled included heart, liver, respiratory organ, colostomy or urostomy, and epilepsy. ChiSquare, t-test, and ANCOVA were conducted, and then the trends for five years were explored through panel analysis.

Results: Of the 308 subjects, 136 (44.2\%) had Kidney Disability and 172 (55.8\%) had Non-Kidney Disabilities. The number of chronic diseases was 4.7 in the Kidney Disabled and 3.3 in the Non-Kidney Disabled $(P<0.001)$. The annual out-of-pocket expenditure for the Kidney Disabled was $\$ 1,310$ and that for the Non-Kidney Disabled $\$ 812(P<0.001)$. Today's subjective health status for the quality of life (from the worst 0 points to the best 100 points ) was 48.9 for the Kidney Disabled and 60.4 for the Non-Kidney Disabled $(P<0.001)$. In addition, the five years trends for the number of chronic diseases, annual out-ofpocket medical expenditure, and quality of life also differed between the Kidney and the Non-Kidney Disabled $(P<0.01)$.

Conclusion: The Kidney Disabled was more serious than the Non-Kidney Disabled in the aspect of the number of chronic diseases, the out-of-pocket medical expenditure, and quality of life. Therefore, it is necessary to consider greater interest in the health care of the Kidney-Disabled people in terms of equity.

\section{Background}

In addition to inequality in modern society, the equity of health is deepening further, which could put more emphasis on health policies. In order to achieve the policy goal of inclusive welfare management, the health level of the disabled should be a major research task. Nevertheless, it is rare to study the health of people with disabilities, especially those with internal-organ disabilities. According to the law on the welfare of the disabled, it means that disabled people have physical or mental disabilities and are significantly restricted in their daily lives or social activities. Types of physical disorders are external-physical and Internal-organ disabled. In Korea, patients with end-stage renal disease (ESRD) who have received dialysis for more than three months or kidney transplantation (KT) can register as the Kidney Disabled.

The ESRD has not only more severity than other chronic diseases but also more medical expenditure absolutely in the world. Renal replacement therapy (RRT) including peritoneal dialysis (PD), hemodialysis (HD) or KT is essential for ESRD. Besides, the key risk factors of ESRD such as diabetes and hypertension have been increased [1]. The prevalence of ESRD among diabetes and hypertension had over 4-10 times in the general population [2-4]. ESRD will be increased more with the aging population and increasing lifespan. Medical expenditure of ESRD will be increased more and more and will be a big problem with their 
remaining life. Therefore, it is possible to predict that the Kidney Disabled persons have a worse degree of severity, medical expenditure, and quality of Life (QOL) than those of Non-Kidney Disabilities.

The increase in ESRD is expected to increase the number of people with kidney disabilities in the future. ESRD, in particular, has already experienced physical and mental crises due to its pathologic nature. They have been frustrated by long-term disease management and high medical spending. Also, due to health difficulties, only about $22 \%$ of HD and $36 \%$ of PD patients worked full-time [5]. The subjects have financial difficulties, and the national burden is increasing. The registered disabled on the act receive a variety of medical benefits compared to the general population. In Korea, people receiving Medical Aid (MA) in general population is about $3 \%$, but the disabled persons receiving MA is about $30 \%$. The burden of government is also increasing more and more.

Public awareness of the seriousness of ESRD is also relatively low compared to cancer and stroke. Compared to the other internal-organ disabled people, information on the Kidney Disabled is relatively poor because of little studies [6]. Therefore, various medical welfare programs suitable for the Kidney Disabled are not actively applied. Also, there have been few studies on multimorbidity, annual OOP expenditure, and QOL for the Kidney disabled [5]. So, we aimed to identify the relative severity between the Kidney and NonKidney Disabled by the number of chronic diseases, annual OOP expenditure, and QOL, using Korea Health Panel (KHP) from 2009 to 2013.

\section{Methods}

\section{Data source}

The study used KHP data co-organized by the Korea Institute for Health and Social Affairs (KIHASA) and the National Health Insurance $(\mathrm{NHI})$ Corporation. KHP data is representative national data that provided scientific data on medical service use, expenditure, health behavior, QOL, etc. The survey was launched in 2008 , and further surveys such as health behaviors and QOL were launched in 2009. The subjects were selected by stratification multistage random sampling and have examined the same or slightly modified variables every year to date. The data are opened to the public for various policy decisions after a data wash period of approximately three years.

This study analyzed longitudinal KHP data without weight. This is because the biasness will be reliable than unbiasness of samples, as the number of people with Internal-organ disabled is small, but all Internal-organ disabled was included. In addition, it is expected that factual identification of subjects since the attrition of the subjects may be due to actual health problems.

We received official data from KIHASA from 2008 to 2013 for this study in 2016. Therefore, we analyzed five years of data from 2009 to 2013, when QOL began to be investigated. This data was officially received by the Agency Review Board (KIHASA 2016-01).

\section{Data collection}


The KHP questionnaire consisted of a household and a household member component. All the variables were examined by a skilled interviewer who visited the family for face-to-face interviews using a computer. In particular, for the accuracy of annual medical use and expenditures, the subject was recorded in the medical diary prepared specially for medical use and expenditures. To this end, the NHI and KIHASA trained the subjects how to store records and receipts.

\section{Analytic variables and study subjects}

Variables used in this study included types of disabilities, gender, age, marriage history, medical assurance, economic activity, number of chronic diseases, annual OOP medical expenditure, and today's subjective health status as QOL (EQ VAS) [7].

Subject to this study are 308 people with the Internal-organ disabled among the panel subjects for a period of five years from 2009 to 2013 . They were only $6.5 \%$ of the 4,732 disabled people in the KHP data in the same period. The disabled in the KHP was registered under the Act on the Welfare of Persons with Disabilities. Among them, Kidney disability consisted of dialysis $(n=115)$ and KT $(n=21)$ and Non-Kidney disability included heart $(n=25)$, respiratory organ $(n=43)$, liver $(n=5)$, colostomy or urostomy $(n=32)$, and epilepsy $(n=67)$. As there are rare Internal-organ disabled, we classified the subjects as the Kidney and Non-Kidney Disabled (heart, respiratory organ, liver, colostomy or urostomy, and epilepsy) for clarity of the results. Because we focused on the distinct characteristics of those with Kidney Disabled among the Internal-organ disabled. Also, the subject sizes for the two groups were different. But to know the factual phenomenon, we did not make the equal of subjects through matching.

\section{Statistical analysis}

The socio-demographic characteristics of the Kidney Disabled and Non-Kidney Disabled were identified through descriptive statistics, $t$ and Chi-Square test. Through ANCOVA, the number of chronic diseases, annual OOP medical expenditure, and today's subjective health status as QOL points (EQ VAS) were determined by comparing the Kidney Disabled and Non-Kidney Disabled. The covariates such as gender, age, marital status, and economic activity were adjusted.

In addition, through the linear panel analysis of fixed effect, five years variation in the number of chronic diseases, annual personal OOP expenditure, and the today's subjective health status as QOL was presented in locally weighted scatter-plot smoother (LOWESS) curve. The statistical significance was then presented after control of the sex and age. The variance of each panel model was also analyzed with a saturated or main effects model with a compound symmetry covariance matrix, depending on the interaction effect.

All expenditure (South Korean Won, KRW) were calculated in USD dollars (\$) as of July 1, 2009 (1\$ = 1,258.59 KRW) [8]. All analyses were conducted after excluding missing data using SAS 9.4 (SAS Institute, Cary, NC, USA). P-values of less than 0.05 were regarded as statistically significant. 


\section{Definitions of terms}

\section{The Internal-organ disabled, Kidney or Non Kidney disabled}

The Internal-organ disabled means people with organ disabilities: kidney, heart, liver, respiratory organ, colostomy or urostomy, and epilepsy. People with internal-organ disabilities need to receive treatment continuously and are hard to get a job due to social prejudice, and often suffer from poverty. So, the disabled are registered under the Act on the Welfare of Persons with Disabilities.

\section{Chronic disease}

Chronic disease (code) means all illness for the last 1 year diagnosed by a medical doctor: Hypertension (I10-I15), Diabetes (E10-E14), Hyperlipidemia (E78), Arthritis (M00-M25), Tuberculosis (A15-A19), Ischemic Heart Disease (120-125), Cerebral Vascular Disease (160-169), and others [9]. In this study, the number of chronic diseases included the main cause of disability. The various chronic disease presented by subjects were inputted and managed as a standardized disease code (KCD6_CODE) each year through the identification of medical services and expenditure used by trained interviewers during data collection.

\section{The OOP medical expenditure}

The OOP medical expenditure refers to the sum of the medical expenditure that individual should co-pay after excluding insurance benefits of visiting the emergency room, admission ward, outpatient department (OPD), and purchasing prescription drugs. Therefore, these were included all OOP medical expenditure for each person with Internal-organ disabled such as cost for dialysis or treatment kidney transplantation (KT) for those with Kidney Disabled. Also, it included expenditure for uncovered services by Medical Social Security Program. Until now, medical cost studies analyzed each hospital's claims data, but studies measuring co-payment in each individual have been rare.

\section{Today's subjective health status as single summary QOL points (EQ VAS)}

EQ visual analogue scale was mark health status on the day of the interview on a vertical scale with endpoints of 0 and 100 . There are notes at both ends of the scale that the bottom rate (0) corresponds to " the worst health you can imagine", and the highest rate (100) corresponds to "the best health you can imagine". A well-known limitation of visual analogue scale is end-of-scale bias that respondents are less likely to use the extreme ends of the scale for rating their health status. However, it is still useful and the simplest direct method for valuing health-related quality of life.[10]

\section{Medical Social Security program}


In Korea, Medical Social Security consists of $\mathrm{NHI}$ and Public MA. NHI is a compulsory system for social security net. Ninty-seven\% of Korean people have $\mathrm{NHI}$ obligatory. Koreans should pay insurance premiums to $\mathrm{NHI}$ according to their income and asset levels. Their co-payment has been from $20 \%$ up to $60 \%$ of the total fee for each medical service $[11,12]$.

Meanwhile, MA supports the lowest income group or the persons with an incapacity for maintaining their life. They pay small co-payment in admission (zero to $10 \%$ of the total fee) and in OPD visit of clinic or hospital (\$0.95 to $15 \%$ of total fee) less than those of $\mathrm{NHI}[12]$.

\section{Results}

\section{Socio-demographic characteristics}

Compared with the demographic characteristics of the Kidney and the Non-Kidney Disabled, the average age was 59.9 and 56.5 ( $p<0.005)$, and proportion of men was $47.8 \%$ and $72.7 \%(p<0.0001)$ respectively. The number of married couples was $69.9 \%$ and $56.4 \%(p<0.002)$, and economic activities are $12.5 \%$ and $33.9 \%$ respectively $(p<0.0002)($ Table1).

Table 1. Socio-demographic Characteristics of the People with Kidney and Non-Kidney Disabilities $^{1)}$ 


\begin{tabular}{|c|c|c|c|c|c|}
\hline \multicolumn{2}{|c|}{ Classification } & $\begin{array}{c}\text { Total } \\
(\%)\end{array}$ & $\begin{array}{c}\text { Kidney } \\
\text { disability(\%) }\end{array}$ & $\begin{array}{c}\text { Non-Kidney } \\
\text { disability } \\
(\%)\end{array}$ & $\begin{array}{l}\text { Chi-Square or } \\
\text { t value/p- } \\
\text { value }\end{array}$ \\
\hline \multicolumn{2}{|r|}{ All } & $308(100.0)$ & $136(100.0)$ & $172(100.0)$ & \\
\hline age & Mean \pm SD & $58.0 \pm 14.8$ & $59.9 \pm 11.5$ & $56.5 \pm 16.9$ & $2.10 /<0.003$ \\
\hline \multirow[t]{2}{*}{ Gender } & Male & $190(61.7)$ & $65(47.8)$ & $125(72.7)$ & \multirow[t]{2}{*}{$19.9<0.0001$} \\
\hline & Female & $118(38.3)$ & $71(52.2)$ & $47(27.3)$ & \\
\hline \multirow[t]{2}{*}{ Age } & $<65$ & $180(58.4)$ & $82(60.3)$ & $98(57.0)$ & \multirow[t]{2}{*}{$0.34 /<0.557$} \\
\hline & $>=65$ & $128(41.6)$ & $54(39.7)$ & $74(43.0)$ & \\
\hline \multirow[t]{3}{*}{ marital status } & Married & $191(62.4)$ & $95(69.9)$ & $96(56.4)$ & \multirow[t]{3}{*}{$12.59 /<0.002$} \\
\hline & $\begin{array}{c}\text { Separated, } \\
\text { divorced }\end{array}$ & $77(25.1)$ & $34(25.0)$ & $43(25.2)$ & \\
\hline & Unmarried & $38(12.4)$ & $7(5.2)$ & $31(18.2)$ & \\
\hline \multirow[t]{2}{*}{ Economic activity } & Yes & $75(24.4)$ & $17(12.5)$ & $58(33.9)$ & \multirow[t]{2}{*}{$18.82 /<0.001$} \\
\hline & No & $232(75.6)$ & $119(87.5)$ & $113(66.1)$ & \\
\hline \multirow[t]{2}{*}{$\begin{array}{l}\text { Medical social } \\
\text { security }\end{array}$} & $\begin{array}{l}\text { National } \\
\text { Health } \\
\text { Insurance }\end{array}$ & $208(67.5)$ & $97(71.3)$ & $111(64.5)$ & \multirow[t]{2}{*}{$1.60 / 0.2$} \\
\hline & Medical Aid & $100(32.4)$ & $39(28.7)$ & $61(35.5)$ & \\
\hline \multirow{2}{*}{$\begin{array}{l}\text { Type of Kidney } \\
\text { disability }\end{array}$} & Dialysis & $115(37.3)$ & $115(84.6)$ & - & \multirow[t]{7}{*}{$308.0 / 0.0001$} \\
\hline & $\begin{array}{c}\text { Kidney } \\
\text { transplantation }\end{array}$ & $21(6.8)$ & $21(15.4)$ & - & \\
\hline \multirow{5}{*}{$\begin{array}{c}\text { Type of Non- } \\
\text { Kidney disability }\end{array}$} & Heart & $25(8.1)$ & - & $25(14.5)$ & \\
\hline & $\begin{array}{c}\text { Respiratory } \\
\text { organ }\end{array}$ & $43(13.9)$ & & $43(25.0)$ & \\
\hline & Liver & $5(1.6)$ & - & $5(2.9)$ & \\
\hline & $\begin{array}{l}\text { colostomy or } \\
\text { urostomy }\end{array}$ & $32(10.4)$ & - & $32(18.6)$ & \\
\hline & epilepsy & $67(21.8)$ & - & $67(39.0)$ & \\
\hline
\end{tabular}

\section{Numbers of chronic diseases}

The number of chronic diseases held was 4.7 for the Kidney Disabled on average, and 3.3 for the NonKidney Disabled on average $(p<0.0001)($ Table2). 
Table 2. Comparison of the Number of Chronic Diseases of the Kidney and Non-Kidney disabled by ANCOVA

\begin{tabular}{|c|c|c|c|c|c|c|c|}
\hline \multirow{2}{*}{ Classification } & \multicolumn{2}{|c|}{ Total } & \multicolumn{2}{|c|}{ Kidney disability ${ }^{1)}$} & \multicolumn{2}{c|}{ Non-Kidney disability ${ }^{2)}$} & \multirow{2}{*}{ F/p-value ${ }^{3)}$} \\
\cline { 2 - 7 } & $\mathrm{n}$ & Number $\pm \mathrm{SE}$ & $\mathrm{n}$ & Number $\pm \mathrm{SE}$ & $\mathrm{n}$ & Number $\pm \mathrm{SE}$ & \\
\hline All & 308 & $3.8 \pm 0.1$ & 136 & $4.7 \pm 0.2$ & 170 & $3.3 \pm 0.2$ & $24.08 /<0.0001$ \\
\hline Male & 190 & $3.9 \pm 0.1$ & 65 & $4.9 \pm 0.3$ & 123 & $3.5 \pm 0.2$ & $11.80 / 0.0007$ \\
\hline Female & 118 & $3.7 \pm 0.2$ & 71 & $4.3 \pm 0.2$ & 47 & $2.9 \pm 0.3$ & $14.95 / 0.0002$ \\
\hline
\end{tabular}

1) Kidney disability consisted of dialysis $(\mathrm{n}=115)$ and $\mathrm{KT}(\mathrm{n}=21)$

2) Non-Kidney disability included heart $(\mathrm{n}=25)$, respiratory organ $(\mathrm{n}=43)$, liver $(\mathrm{n}=5)$, colostomy or urostomy $(\mathrm{n}=32)$, and epilepsy (n=67). |

3) The covariate variables were gender, age, marital status, and economic activity.

\section{Annual OOP medical expenditure for 1 year}

For a year, the annual OOP medical expenditure was about $\$ 1,310$ for the Kidney Disabled and $\$ 832$ for the Non-Kidney disabled $(P<0.005)$ (Table3).

Table 3. Annual OOP medical expenditure ${ }^{1)}$ for the Kidney and the Non-Kidney Disabled by ANCOVA

\begin{tabular}{|c|c|c|c|c|c|c|c|}
\hline & Classification & \multicolumn{3}{|c|}{ Total } & \multicolumn{2}{|c|}{ Kidney disability $^{2)}$} & \multicolumn{2}{|c|}{$\begin{array}{c}\text { Non-Kidney disability } \\
\text { 3) }\end{array}$} & \multirow{2}{*}{ F/p-value ${ }^{4)}$} \\
\cline { 2 - 7 } & $\mathrm{n}$ & Means \pm SE & $\mathrm{n}$ & Means \pm SE & $\mathrm{n}$ & Means $\pm S E$ & \\
\hline All & 307 & $1,045.2 \pm 77.0$ & 136 & $1,310.6 \pm 115.8$ & 169 & $832.6 \pm 103.0$ & $8.83 /<0.004$ \\
\hline Male & 189 & $914.9 \pm 79.9$ & 65 & $1,165.1 \pm 130.5$ & 122 & $780.8 \pm 93.4$ & $13.99 / 0.0002$ \\
\hline Female & 118 & $1,254.0 \pm 152.8$ & 71 & $1,517.3 \pm 197.9$ & 47 & $856.2 \pm 245.1$ & $4.26 / 0.0414$ \\
\hline
\end{tabular}

1) Including cost for an emergency room visit, out-patient department visit, admission and buying for the prescribed drug. Every expenditure converted to USD (\$) based on the exchange rate on July 1, 2009 ( 1 \$= 1,258.59 KRW).

2) Kidney disability consisted of dialysis $(\mathrm{n}=115)$ and $\mathrm{KT}(\mathrm{n}=21)$ patients.

3) Non-Kidney disability included heart $(n=25)$, respiratory organ $(n=43)$, liver $(n=5)$, and colostomy or urostomy $(\mathrm{n}=32)$, and epilepsy $(\mathrm{n}=67)$.

4) The covariates were gender, age, marital status, and economic activity. 


\section{Today's subjective health status as QOL (EQ VAS)}

The result showed that among the best points (100), the average response points for the Kidney Disabled was 48.9 , which was lower than 60.4 for the Non-Kidney disabled (Table4).

Table 4. Comparison of the kidney and the non-kidney disabled QOL (EQ VAS) by ANCOVA

\begin{tabular}{|l|c|c|c|c|}
\hline Classification & Total & Kidney disability 1$)$ & Non-Kidney disability 2$)$ & F/p-value \\
& $\mathrm{n}=271$ & $\mathrm{n}=130$ & $\mathrm{n}=141$ & \\
\hline Today's health status & $54.9 \pm 1.2$ & $48.9 \pm 1.8$ & $60.4 \pm 1.7$ & $20.73 /<0.0001$ \\
$(0$ worst-100 Best $)$ & & & & \\
\cline { 1 - 3 } 25th, Median, 75th & $40,50,70$ & $40,50,70$ & $50,60,70$ & \\
\hline
\end{tabular}

1) Kidney disability consisted of dialysis $(n=115)$ and KT $(n=21)$ patients.

2) Non-Kidney disability included heart $(n=25)$, respiratory organ $(n=43)$, liver $(n=5)$, and colostomy or urostomy $(\mathrm{n}=32)$, and epilepsy $(\mathrm{n}=67)$.

3) The covariates were gender, age, marital status, and economic activity.

\section{The trends over five years of the number of chronic diseases, OOP medical expenditure, and QOL}

From 2009 to 2013, five years of data were used to identify trends in the number of chronic diseases, annual OOP medical expenditure, and QOL through panel analysis. As a result, in all five years, the kidney disabled were worse than those with the non-kidney disabled $(p<0.01)$ (Fig1).

Fig 1. Five years of trends of chronic disease numbers, the OOP expenditure and QOL in both groups by fixed effect panel model

Thick red dotted lines refered to LOWESS curve, and other lines refered to the value of each subject

\section{Discussion}

ESRD is a disease that accumulates uremic toxin due to almost no kidney function. ESRD patients will continue to increase exponentially with aging populations and an increase in the incidence of chronic diseases such as diabetes and high blood pressure [5]. ESRD is managed by RRT such as KT or dialysis. So, the patients' lifespan will be also increased more and more [5]. In Korea, the number of patients receiving RRT increased to 75,042 in 2013 and 80,674 in 2014 [13, 14]. Therefore, the Kidney Disabled who receive KT or dialysis with ESRD will increase further in the future, and the burden of the nation will also increase. 
ESRD is a chronic and severe disease that requires long-term care with high-cost medical care such as RRT. ESRD patients are severely limited to full-time activity over a long period of time. As a result, only about 22 percent of HD and 36 percent of PD patients work full-time [5]. Nevertheless, studies on the personal OOP burden and the QOL caused by ESRD are rare, and studies on the health severity of the Kidney Disabled due to ESRD are even very rare. Therefore, this study targeted comparisons of severity between the Kidney Disabled and Non-Kidney Disabled by the number of chronic diseases, annual OOP medical expenditure, and the QOL.

In our research, $28.7 \%$ of the Kidney Disabled had MA lower than 35.5\% of the Non-Kidney Disabled. The OOP medical expenditure burden in NHI was higher than MA. In addition, the economic activity of the NonKidney Disabled was $33.9 \%$ while only $12.5 \%$ of the Kidney Disabled. It reflected that the latter subjects required a lot of time to treat and had a quite difficult situation to sustain a job. In the previous study, it was similar that only a small percentage had economic activity in ESRD [15-18]. Therefore, it needs to consider the medical welfare policy about OOP expenditure in the Kidney Disabled, especially than others. It needs not the only improvement about the negative perception for the disabled, but also labor policy to ensure livelihood security through national benefit enforcement for the employer to employ the kidney disabled.

Twenty-Five percent of the U.S. adult population had at least 2 chronic diseases, which were the critical etiology of mortality [19]. Patients with ESRD had a larger comorbidity burden [20]. It was similar to our study results. In this study, the number of chronic diseases was 4.7 in the Kidney Disabled and 3.3 of the Non-Kidney Disabled $(\mathrm{P}<0.001)$. In addition, trends over five years in the number of chronic diseases between the Kidney Disabled and Non-Kidney Disabled also showed a significant difference $(P<0.01)$.

In other country, Medicare beneficiaries with ESRD would have approximately twice OOP expenditure than that of Medicare in Non-ESRD [21]. In our study, annual OOP medical expenditure was \$1,310 in the Kidney Disabled and $\$ 832$ in the Non-Kidney Disabled $(P<0.001)$. Trend over five years of annual OOP medical expenditure showed a significant difference between the Kidney Disabled and the Non-Kidney Disabled $(P<0.001)$.

In the previous study, the QOL of ESRD was lower than Non-ESRD, especially the QOL in five domains index including Mobility, Usual Activities, and Pain/Discomfort [22]. In this study, today's subjective health status for QOL points (EQ VAS) showed a significant difference between 48.9 points for the Kidney Disabled and 60.4 points for non-kidney disabled $(P<0.001)$. From 2009 to 2013 , five years of data were used to identify trend in QOL through panel analysis. As a result, in all five years, the Kidney Disabled had lower QOL than the non-kidney disabled $(p<0.01)$.

The limitation of our study as follows: First, it did not consider the cost of over-the-count medicine or herbdrug. So, the OOP medical expenditure in this study may be underestimated. Second, since the number of Internal-organ disabled was not large, the Kidney-Disabled and all other Internal-organ disabled were grouped and compared. Therefore, different characteristics of each disability were not considered. Third, the raw material already combined subjects with the KT and dialysis and a small number of KT, so we are not able to analyze the difference between the KT and dialysis. Further research comparing the KT and dialysis will be recommended. 
Nonetheless, the strength of this study as follows: First, the financial burden from the OOP medical expenditure was identified in the Kidney Disabled. In most countries, even though the financial burden due to ESRD was a critical issue, there were studies only about health insurance expenditure, but few studies about the OOP medical expenditure. Second, multimorbidity and QOL being the poorest in the Kidney Disabled will provide the evidence for medical policy, and prioritizing for the medical agenda is crucial in the effectiveness. Third, studies on the health level of people with Internal-organ disabled, especially those with Kidney Disabled, are very rare. Therefore, the study could provide key information on the equity of health policies among the disabled.

\section{Conclusion}

Unlike the surrounding phenomenon that the situation of household bankruptcy caused by diseases in the Internal-organ disable is serious, there have been few studies on the burden and QOL of those with the Internal-organ disabled. In this study, the Kidney Disabled was more serious than the Non-Kidney Disabled in terms of the number of chronic diseases, the OOP medical expenditure, and QOL. This is consistent with previous studies suggesting that ESRD is a more serious health issue than all other chronic diseases such as cancer and stroke [23-25]. Therefore, it is necessary to consider greater interest in the health care of the Kidney-Disabled people in terms of equity.

\section{Declarations}

\section{Acknowledgements}

None

\section{Funding}

This paper was supported by Joongbu University Research \& Development Fund, in 2018.

\section{Availability of data and materials}

We submitted a research plan to the Korea Health Panel (KHP) Data Management Institution (KIHASA) and officially transferred the data. Other researchers can also take over the data upon request. This information was directed to the following link sites: https://www.khp.re.kr:444/eng/main.do

\section{Authors' contributions}

Sun Mi Shin and Hee Woo Lee were the main researchers, participated in the design and drafted and edited the article. Sun Mi Shin participated in the design of the study and conducted the statistical analysis. Hee Woo Lee participated in the validation of the quality and edited the manuscript. All fields were completed by authors. 


\section{Authors' information}

Sun Mi Shin, Ph D., Hee Woo Lee, MD, Ph D. ${ }^{1}$ Associate professor, Department of Nursing, Joongbu University, ${ }^{1}$ Director, Hemodialysis Unit, Lee Hee Woo Internal Medicine Clinic ORCID

Sun Mi Shin: 0000-0002-5519-2412, Hee Woo Lee: 0000-0002-0327-3632

First author

. Name: Sun Mi Shin, Ph.D.

Department of Nursing, Joongbu University, Korea

. Address: Joongbu University, 201 Daehak-ro, Chubu-myeon, Geumsan-gun,

Chungnam, Korea

. Telephone number: Office $82-41-750-6255 /$ Cell phone 82-10-9288-5177

. FAX number: 82-41-750-6166

.E-mail: healthteam@joongbu.ac.kr

.Zip code: 32713

Corresponding author

. Name: Hee Woo Lee ${ }^{1}$, M. D. Ph. D.

${ }^{1}$ Lee Hee Woo Internal Medicine Clinic, Hemodialysis Unit

. Address,

1402, Gyebaek-ro, Seo-gu, Daejeon, Korea

. Telephone number,

Office $82-42-587-3110$

Cell phone 82-10-8736-5203

. FAX number: 82-42-587-3109

.E-mail address:md.leehw@gmail.com

.Zip code: 35400

\section{Conflict of interest statement}

None declared. 


\section{Consent for publication}

Not applicable.

\section{Ethics approval and consent to participate}

The KHP study was approved by the Institutional Review Board (KIHASA 2016-01) in Korea.

We can submit an IRB translated into English to prove this.

\section{References}

1. Moeller S, Gioberge S, Brown G. ESRD patients in 2001: global overview of patients, treatment modalities and development trends. Nephrol Dial Transplant 2002; 17: 2071-76.

2. Foley RN, Hakim RM. Why is the mortality of dialysis patients in the United States much higher than the rest of the world? J Am Soc Nephrol 2009; 20: 1432-35. doi: 10.1681/ASN.2009030282.

3. Gao D, Jing S, Wu J, Wu G. Economic Burden and Medical Insurance Impact of the Different Dialysis for End-stage Renal Diseases. Iran J Public Health 2018; 47: 1675-80.

4. Seok SJ, Kim JH, Gil HW, Yang JO, Lee EY, Hong SY. Comparison of patients starting hemodialysis with those underwent hemodialysis 15 years ago at the same dialysis center in Korea. Korean $\mathrm{J}$ Intern Med 2010; 25: 188-94. doi: 10.3904/kjim.2010.25.2.188

5. Jin DC, Yun SR, Lee SW, et al. Lessons from 30 years' data of Korean end-stage renal disease registry, 1985-2015. Kidney Res Clin Pract 2015; 34: 132-39. doi: 10.1016/j.krcp.2015.08.004

6. Roomizadeh P, Taheri D, Abedini A, et al. Limited knowledge of chronic kidney disease and its main risk factors among Iranian community: an appeal for promoting national public health education programs. Int J Health Policy Manag 2014; 24: 161-6. doi: 10.15171/ijhpm.2014.37

7. The EuroQol Group. EuroQol-a new facility for the measurement of health-related quality of life. Health Policy 1990; 16: 199-208.

8. Historic Exchange Rates (South Korean Won) [internet]. [cited 2019 February 22]. Available from: http://www.x-rates.com/historical/ from $=$ KRW\&amount $=1$ \&date $=2017-07-20$

9. Questionnaire in Korea Health panel Survey [internet]. [cited 2019 February 22]. Available from: https://www.khp.re.kr:444/web/data/board/list.do?bbsid = 54EQ-5D-3L User Guide [internet]. [cited 2019 February 22]. Available from: https://euroqol.org/publications/user-guides

10. Whitehead SJ, Ali S. Health outcomes in economic evaluation: the QALY and utilities. Br Med Bull 2010; 96: 5-21. doi: 10.1093/bmb/ldq33

11. Lee JE, Shin HI, Do YK, Yang EJ. Catastrophic health expenditures for households with disabled members: evidence from the Korean Health Panel. J Korean Med Sci 2016; 31: 336-44. doi: 10.3346/jkms.2016.31.3.336

12. Korea Insurance Charge Review Association [internet]. [cited 2019 February 22]. Available from: http://www.hicra.or.kr/sub_asp/04_data06_2.html 
13. Jin DC. Dialysis registries in the world: Korean Dialysis Registry. Kidney Int (Suppl 2011) 2015; 5: 8-11.

14. Jin DC, Yun SR, Lee SW, Han SW, Kim W, Park J. Current characteristics of dialysis therapy in Korea: 2015 registry data focusing on elderly patients. Kidney Res Clin Pract 2016; 35: 204-11.

15. Bertolin DC, Pace AE, Kusumota L, Haas V. An association between forms of coping and the sociodemographic variables of people on chronic hemodialysis. Rev Esc Enferm 2011; 45: 1070-76.

16. Teo BW, Ma V, Xu H, Li J, Lee EJ; Nephrology Clinical Research Group. Nephrology Clinical Research Group. Profile of hospitalisation and death in the first year after diagnosis of End-stage Renal Disease in a multi-ethnic Asian population. Ann Acad Med Singapore 2010; 39: 79-87.

17. Hogan AN, Fox WR, Roppolo LP, Suter RE. Emergent dialysis and its impact on quality of life in undocumented patients with End-stage Renal Disease. Ethn Dis 2017; 27: 39-44. doi: 10.18865/ed.27.1.39

18. Ramachandran R, Jha V. Kidney transplantation is associated with catastrophic out of pocket expenditure in India. PLoS One 2013; 8: e67812. doi: 10.1371/journal.pone.0067812. Print 2013

19. Ward BW, Black LI. State and Regional Prevalence of Diagnosed Multiple Chronic Conditions Among Adults Aged $\geq 18$ Years - United States, 2014. MMWR Morb Mortal Wkly Rep 2016; 65: 735-8. doi: 10.15585/mmwr.mm6529a3

20. Krishnaswami A, Kiley ML, Anthony FF, et al. Effect of advancing age and multiple chronic conditions on mortality in patients with End-Stage Renal Disease after implantable cardioverter-defibrillator placement. Perm J. Winter 2016; 20: 27-32. doi: 10.7812/TPP/15-084

21. Patel UD, Davis MM. Falling into the doughnut hole: drug spending among beneficiaries with end-stage renal disease under Medicare Part D plans. J Am Soc Nephrol 2006; 17: 2546-53.

22. Balaban ÖD, Aydin E Keyvan A, Yazar MS, Tuna Ö, Devrimci Özgüven H. Psychiatric comorbidity, sexual Dysfunction, and quality of life in patients undergoing hemodialysis: A case-control study. Noro Psikiyatr Ars 2017; 54: 137-42. doi: 10.5152/npa.2016.12677

23. Schneider K, O’Donnell BE, Dean D. Prevalence of multiple chronic conditions in the United States' Medicare population. Health Qual Life Outcomes 2009; 7: 82. doi: 10.1186/1477-7525-7-82

24. Fraser SD, Roderick PJ, May CR, et al. The burden of comorbidity in people with chronic kdieny disease stage 3: A cohort study. BMC Nephrol 2015; 16: 193. doi: 10.1186/s12882-015-0189-z

25. Small C, Kramer HJ, Griffin KA, et al. Non-dialysis dependent chronic kidney disease is associated with high total and out-of-pocket healthcare expenditures. BMC Nephrol 2017; 18: 3. doi: 10.1186/s12882016-0432-2

\section{Figures}




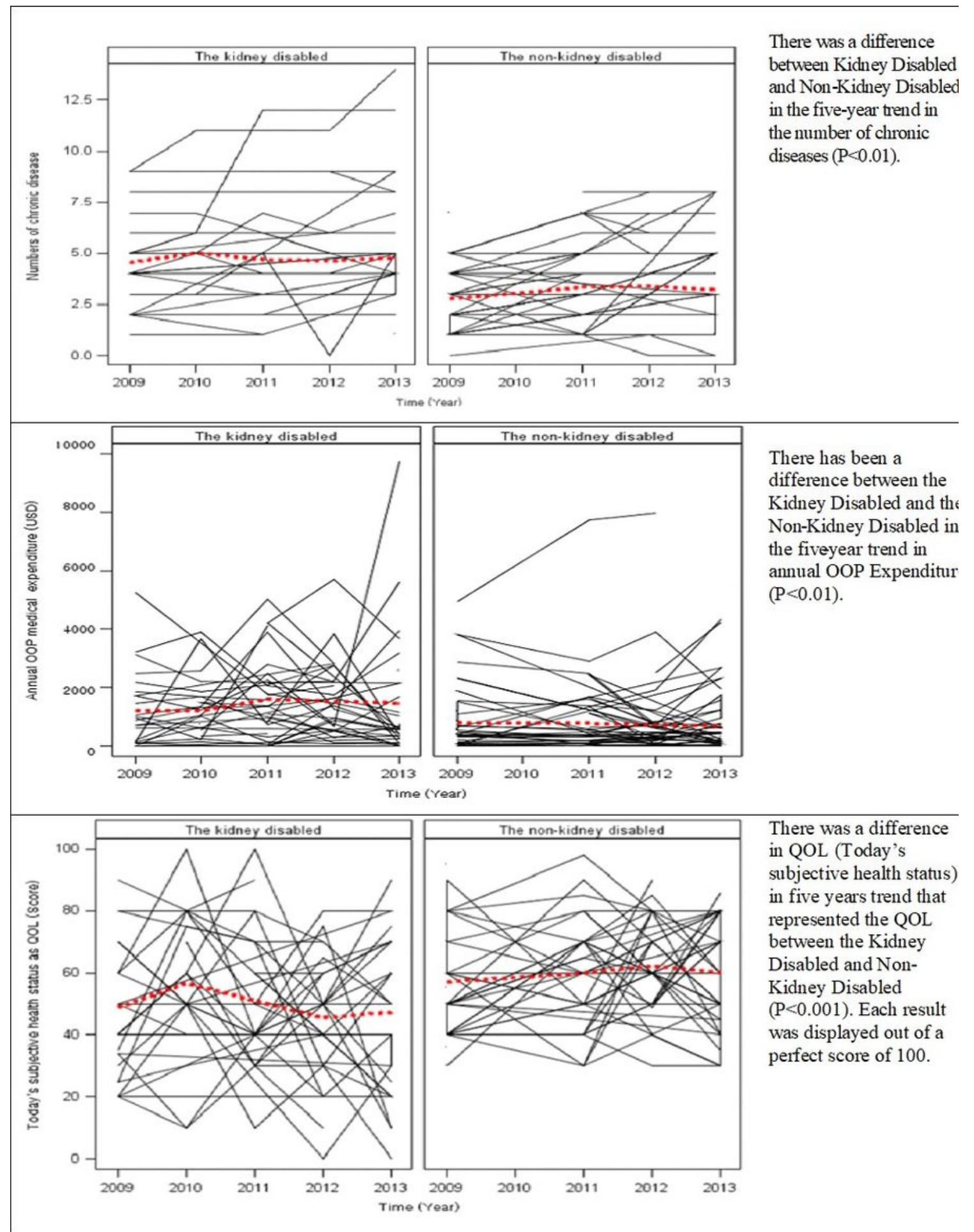

\section{Figure 1}

Five years of trends of chronic disease numbers, the OOP expenditure and QOL in both groups by fixed effect panel model Thick red dotted lines refered to LOWESS curve, and other lines refered to the value of each subject 